\title{
Safety of adenosine stress perfusion cardiac magnetic resonance imaging in patients with aortic stenosis
}

\author{
Stephen Darty \\ From 2011 SCMR/Euro CMR Joint Scientific Sessions \\ Nice, France. 3-6 February 2011
}

\section{Background}

Aortic stenosis (AS) is a relative contraindication to exercise, but the safety of adenosine stress perfusion cardiac magnetic resonance imaging (CMR) in patients with AS is unknown. The primary objective of this study was to determine the safety of adenosine perfusion CMR in patients with AS.

\section{Methods}

Consecutive patients with known or suspected coronary artery disease (CAD) and native aortic valve stenosis (aortic valve area [AVA] $<2 \mathrm{~cm}^{2}$ by planimetry), undergoing adenosine perfusion CMR were eligible for enrollment. CMR imaging included cine, first-pass perfusion at stress and rest, and delayed-enhancement imaging. CMR images were interpreted for CAD using an algorithm previously described by our group (Klem JACC 2006;47:1630-8).

\section{Results}

112 patients with mean age $76 \pm 11$ yrs ( $52 \%$ female) were enrolled. Over all, 16\%, 42\%, and $41 \%$ has severe (AVA $<1 \mathrm{~cm}^{2}$ ), moderate (AVA 1-1.5 $\mathrm{cm}^{2}$ ), and mild (AVA $>1.5 \mathrm{~cm}^{2}$ ) AS. A mean dose of $31 \pm 10 \mathrm{mg}$ adenosine was infused over $2.8 \pm 0.5$ minutes. There were only 2 adverse events, both of which were transient. In the first patient $\left(A V A=1.0 \mathrm{~cm}^{2}\right)$ there was a sinus pause of 3 seconds, and the stress protocol and imaging were completed. In the second patient $\left(\mathrm{AVA}=1.1 \mathrm{~cm}^{2}\right)$, there was prolonged chest pain with bradycardia and hypotension requiring discontinuation of adenosine. Symptoms resolved within 5 minutes without any further intervention. In both patients, pre

and post stress ECG's were unchanged. Diagnostic examinations were completed in 111 of 112 patients. Based on these results and using the exact method we estimate the 95\% confidence intervals (CI) for the occurrence of a severe adverse event is $0-2.6 \%$ and transient (non-severe) event is $0.3-5.5 \%$. Figure 1 shows an example of a positive stress perfusion study in a patient with severe AS $\left(\mathrm{AVA}=0.9 \mathrm{~cm}^{2}\right) .57$ of 111 patients (51\%) had stress CMR studies indicative of significant CAD.

\section{Conclusions}

Adenosine perfusion CMR is a safe alternative for noninvasive stress testing in patients with mild to severe AS.

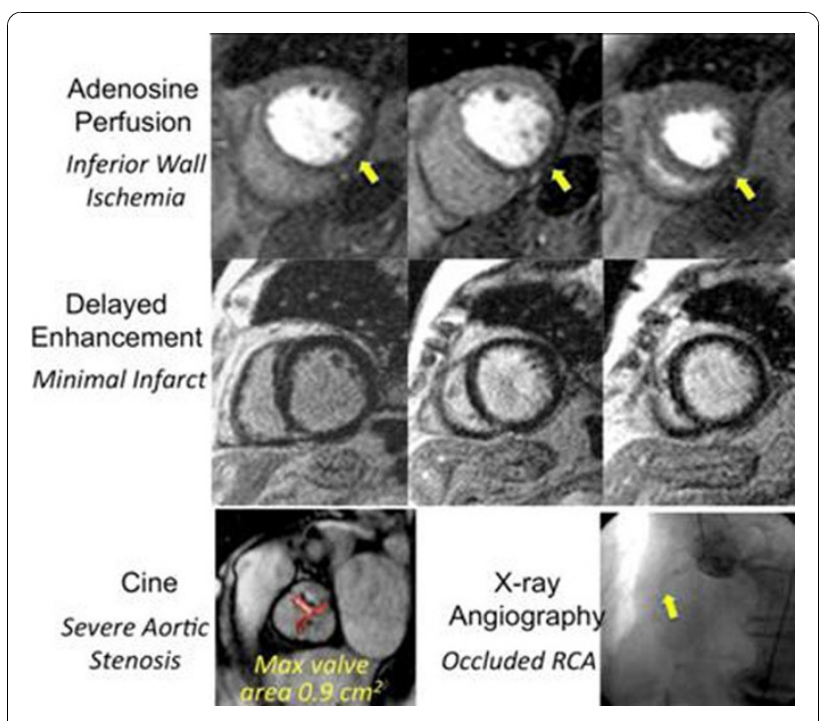

Figure 1

Duke Cardiovascular Magnetic Resonance Center, Durham, NC, USA

( 2011 Darty; licensee BioMed Central Ltd. This is an open access article distributed under the terms of the Creative Commons Attribution License (http://creativecommons.org/licenses/by/2.0), which permits unrestricted use, distribution, and reproduction in any medium, provided the original work is properly cited. 
doi:10.1186/1532-429X-13-S1-038

Cite this article as: Darty: Safety of adenosine stress perfusion cardiac magnetic resonance imaging in patients with aortic stenosis. Journal of Cardiovascular Magnetic Resonance 2011 13(Suppl 1):O38.

Submit your next manuscript to BioMed Central and take full advantage of:

- Convenient online submission

- Thorough peer review

- No space constraints or color figure charges

- Immediate publication on acceptance

- Inclusion in PubMed, CAS, Scopus and Google Scholar

- Research which is freely available for redistribution

Submit your manuscript at www.biomedcentral.com/submit
C Biomed Central 